\title{
A system for quantitative evaluation of the fertility of tropical soils (QUEFTS)
}

\author{
B.H. Janssen ${ }^{1}$, F.C.T. Guiking ${ }^{1}$, D. van der Eijk ${ }^{1}$, E.M.A. Smaling ${ }^{1}$, J. Wolf ${ }^{2}$ and \\ H. van Reuler ${ }^{1}$ \\ 'Department Soil Science and Plant Nutrition, Agricultural University of Wageningen, P.O. Box 8005, \\ 6700 EC Wageningen (The Netherlands) \\ ${ }^{2}$ Centre for World Food Studies, P.O. Box 14, 6700 AA Wageningen (The Netherlands)
}

(Received August 19, 1987; accepted after revision June 21, 1989)

\begin{abstract}
Janssen, B.H., Guiking, F.C.T., van der Eijk, D., Smaling, E.M.A., Wolf, J. and van Reuler, H., 1990. A system for quantitative evaluation of the fertility of tropical soils (QUEFTS). Geoderma, 46: 299-318.

A system is described for a quantitative evaluation of the native fertility of tropical soils, using calculated yields of unfertilized maize as a yardstick. The system is applicable to well drained, deep soils, that have a pH $\left(\mathrm{H}_{2} \mathrm{O}\right)$ in the range 4.5-7.0, and values for organic carbon, P-Olsen and exchangeable potassium below $70 \mathrm{~g} / \mathrm{kg}, 30 \mathrm{mg} / \mathrm{kg}$ and $30 \mathrm{mmol} / \mathrm{kg}$, respectively $(0-20 \mathrm{~cm})$. Soil fertility is interpreted as the capacity of a soil to provide plants with nitrogen, phosphorus and potassium, but the methodology allows for including other nutrients.

The procedure consists of four successive steps. First the potential supplies of nitrogen, phosphorus and potassium are calculated, applying relationships between chemical properties of the $0-20 \mathrm{~cm}$ soil layer and the maximum quantity of those nutrients that can be taken up by maize, if no other nutrients and no other growth factors are yield-limiting. In the second step the actual uptake of each nutrient is calculated as a function of the potential supply of that nutrient, taking into account the potential supplies of the other two nutrients. Step 3 comprises the establishment of three yield ranges, as depending on the actual uptakes of nitrogen, phosphorus, and potassium, respectively. Next, these yield ranges are combined in pairs, and the yields estimated for pairs of nutrients are averaged to obtain an ultimate yield estimate (Step 4).

The relationships used in Steps 1 and 3 were derived from empirical data of field trials in Suriname and in two strongly different agro-ecological zones in Kenya. The equations developed for Steps 2 and 4 were mainly based on theoretical considerations. The equations used to calculate the potential supplies of nutrients (Step 1) should be applied only to soils with the indicated properties. The other equations are more generally applicable. Examples are given to elucidate the procedure. QUEFTS may be a very useful tool in quantitative land evaluation. Its principles may be applied to other crops, soils, nutrients and agro-ecological regions than those involved in this study.
\end{abstract}


INTRODUCTION

Where the use of fertilizers is very limited, like in many tropical areas, crops mostly depend upon the soil nutrients only. Availability of nutrients is then one of the major land qualities to be considered in land evaluation studies. This land quality is usually rated as low, medium or high (FAO, 1976), but the meanings of those words are seldom given in quantitative terms. There is obviously a need for an evaluation system that does supply quantitative information.

This paper describes such a system. It is called QUEFTS: Quantitative Evaluation of the Fertility of Tropical Soils. In the system, chemical soil fertility is conceived as the capacity of a soil to provide plants with nutrients. In many unfertilized soils, crop growth is limited by a low supply of one or more of the major nutrients N,P and K, while there is a relatively ample supply of secondary and trace elements. Therefore the QUEFTS system is as yet restricted to an appraisal of the status of N,P and $\mathrm{K}$. Yields are calculated as a function of the availability of these nutrients, for which organic carbon, $\mathrm{P}$ Olsen, exchangeable potassium and $\mathrm{pH}\left(\mathrm{H}_{2} \mathrm{O}\right)$ act as diagnostic criteria. When applying the system it is essential that crop growth is not hampered by other factors such as moisture deficit, waterlogging, restricted root penetration and poor crop husbandry practices. Soils should be deep and well drained. The values of the diagnostic properties should lie within the ranges for which QUEFTS was tested: $\mathrm{pH}\left(\mathrm{H}_{2} \mathrm{O}\right)$ between 4.5 and 7.0 ; organic $\mathrm{C}$ less than 70 $\mathrm{g} / \mathrm{kg}$; P-Olsen less than $30 \mathrm{mg} / \mathrm{kg}$; exchangeable $\mathrm{K}$ less than $30 \mathrm{mmol} / \mathrm{kg}$.

The system has been set up with maize as test crop. Maize was chosen because it is the main food crop in Kenya and in many other tropical regions. Moreover, it is grown under a wide range of climatic and soil conditions, and it is a demanding crop and therefore suited to indicate the potential supply of nutrients by the soil. It is possible, however, to modify this system in such a way as to make it applicable to other crops.

QUEFTS was developed in the course of three projects in tropical countries. Two were general-purpose land evaluation projects in entirely different settings in Kenya. The first was in Kisii District, West Kenya, with an average annual rainfall of 1200 to $2200 \mathrm{~mm}$, depending on altitude ranging from 1200 to $2200 \mathrm{~m}$; most soils are rich (Paleudolls, Hapludolls) but they have low contents of plant-available phosphorus (Wielemaker and Boxem, 1983). The second project was in Kilifi District, coastal area of Kenya, with an average annual rainfall decreasing from $1200 \mathrm{~mm}$ at the coast to $700 \mathrm{~mm}$ land-inward; altitude is from 10 to $300 \mathrm{~m}$; most soils are poor (Haplustox, Quartzipsamment) especially in nitrogen and often also in phosphorus (Boxem et al., 1987). The third project, dealing with mechanized annual cropping, was in Suriname with an average annual rainfall of $2200 \mathrm{~mm}$; altitude is from 10 
to $50 \mathrm{~m}$; soils are extremely poor and acid (Haplorthox, Quartzipsamment) with deficiencies in all primary and secondary nutrients (Boxman et al., 1985).

\section{MAIN CONCEPTS USED IN QUEFTS}

In the system a distinction is made between the potential supply and the actual uptake of a nutrient.

In the soil, nutrients are made available to crops by processes like mineralization of organic matter and weathering of minerals. Often the supplies of the different nutrients are not in balance compared to the needs of a crop. When the supply of a particular nutrient is small in relation to those of other nutrients, the whole supply of that nutrient will be taken up by the crop. When the supply of a particular nutrient is large compared to those of other nutrients, crop growth is limited by the low availability of those other nutrients and the crop cannot make use of the whole supply of the particular nutrient. Then the actual uptake is less than the potential supply. Thus, the potential supply of a nutrient is the maximum quantity that can be taken up, and the actual uptake of a nutrient equals the potential supply only if all other growth conditions are optimum.

In many fertilizer trials it has been observed that crops take up less nutrients than are potentially available. Some examples are given in Table I, where in most cases the uptake of nitrogen increased upon application of fertilizer phosphorus. The ratio of nitrogen uptake (right-hand column) ranges from 0.26 to about 1 , more or less related to an increase in P-Olsen from 1.6 to 5.1. This indicates that especially on soils low in phosphorus, crops took up less than the maximum amount of nitrogen, if no fertilizer phosphorus was

\section{TABLE I}

Nitrogen uptake by maize $(\mathrm{kg} / \mathrm{ha})$ as affected by phosphorus application on soils with different organic carbon and P-Olsen values (data from C.A.J.M. de Bie and J. de Koning, pers. commun., 1982)

\begin{tabular}{|c|c|c|c|c|c|}
\hline \multirow{2}{*}{$\begin{array}{l}\text { Field } \\
\text { code }\end{array}$} & \multirow{2}{*}{$\begin{array}{l}\text { Org. C } \\
(\mathrm{g} / \mathrm{kg})\end{array}$} & \multirow{2}{*}{$\begin{array}{l}\text { P-Olsen*2 } \\
(\mathrm{mg} / \mathrm{kg})\end{array}$} & \multicolumn{3}{|c|}{ N-uptake } \\
\hline & & & $\begin{array}{l}\text { no } P \\
\text { applied }\end{array}$ & $\begin{array}{l}\text { fertilizer } \\
\text { P applied }\end{array}$ & $\begin{array}{l}\text { ratio } \\
-\mathrm{P} /+\mathrm{P}\end{array}$ \\
\hline$R G^{* 1}$ & 23 & 1.6 & 24 & 94 & 0.26 \\
\hline MK & 11 & 2.6 & 30 & 80 & 0.38 \\
\hline $\mathrm{IB}^{* 1}$ & 35 & 2.4 & 87 & 153 & 0.57 \\
\hline SH & 17 & 3.5 & 34 & 52 & 0.65 \\
\hline $\mathrm{CS}$ & 5 & 4.4 & 27 & 41 & 0.66 \\
\hline MS & 9 & 4.6 & 36 & 54 & 0.67 \\
\hline LS & 22 & 4.5 & 42 & 42 & 1.00 \\
\hline $\mathrm{MZ}$ & 5 & 5.1 & 34 & 30 & 1.13 \\
\hline
\end{tabular}

*'These soils received $80 \mathrm{~kg} / \mathrm{ha}$ fertilizer $\mathrm{N}$.

${ }^{* 2}$ The P-Olsen values refer to soils that did not receive fertilizer phosphorus. 
applied. It is an illustration of Liebig's law of the minimum. Many examples of such situations can be found in the literature, as shown by Van Keulen and Van Heemst (1982).

The pivot of QUEFTS is formed by the relations between nutrient uptake and yield. Such relations might vary considerably. When a nutrient is poorly available compared to the other nutrients and growth factors, it is diluted in the plant and its content goes down to a minimum value; the ratio of yield and nutrient uptake has then its maximum value. On the contrary, when a nutrient is abundantly available it accumulates in the plant till its content reaches a maximum value; the ratio of yield and nutrient uptake has then its minimum value. Given a certain uptake of $\mathrm{N}, \mathrm{P}$ or $\mathrm{K}$, the possible yield range is from the yields that correspond with maximum accumulation to the yields that correspond with maximum dilution.

\section{EXPERIMENTAL DATA}

The field trials conducted in the abovementioned projects had been designed for other purposes than the development of a system for quantitative evaluation of soil fertility. QUEFTS was as it were a by-product.

Two types of empirical relationships were derived from the experimental data: those between chemical soil properties and potential nutrient supply and those between actual nutrient uptake and yield. Data on the potential supply of nutrients were obtained after chemical analysis of maize that had received appropriate fertilizers. For instance, the potential supply of nitrogen was determined by analyzing maize that had received phosphorus and potassium fertilizers, at sufficiently high rates, but not no nitrogen fertilizers. In these field trials there were no other obvious soil-borne growth limiting factors, but due to weather conditions the measured potential supplies could considerably fluctuate from season to season. For the comparison with soil data average potential supplies were used.

The potential supply of a nutrient proved related to more than just one soil property. It appeared crucial to consider simultaneously the levels of various soil properties. The number of diagnostic properties was kept at a minimum. Only properties that are almost always determined in simple routine soil surveys were used. Of the 10 to 20 soil properties investigated, four proved best serving the purposes: $\mathrm{pH}\left(\mathrm{H}_{2} \mathrm{O}\right)$, organic carbon, $\mathrm{P}-\mathrm{Olsen}$, and exchangeable potassium. Additional, mostly confirmative, information can be derived from organic nitrogen and total $\mathrm{P}$. The following analytical procedures were used: $\mathrm{pH}$ in supernatant liquid of a $1: 2.5$ soil-water suspension, shaking time $2 \mathrm{~h}$; organic carbon: oxidation by $\mathrm{K}_{2} \mathrm{Cr}_{2} \mathrm{O}_{7}$, correction factor of 1.03 ; organic nitrogen: digestion with concentrated $\mathrm{H}_{2} \mathrm{SO}_{4}$ and salicylic acid; P-Olsen: $5 \mathrm{~g}$ of soil in $100 \mathrm{ml} 0.5 \mathrm{M} \mathrm{NaHCO}_{3}$, pH adjusted to 8.5 , shaking time $30 \mathrm{~min}$; total 
P: digestion with Fleischmann's acid, ratio 2.5:20; exchangeable potassium: percolation with $1 M \mathrm{NH} 4$-acetate.

In the original project papers the diagnostic properties were translated into several classes of nutrient availability (Guiking et al., 1983; Janssen et al., 1986; Smaling and Janssen, 1987). These relationships are now described by equations (Table II) discussed below (Step 1).

The relationships between actual uptake and yield have been established for each of the nutrients nitrogen, phosphorus and potassium, using data for fertilized and for unfertilized maize (Fig. 1). Yield refers to grain yield, and uptake to the amount of nutrients present in all above-ground plant components. Plant density was around 50,000 plants ha. For potassium about 120 data were available and for nitrogen and phosphorus each about 150 . For convenience, in Fig. 1 not the individual points are shown but only the upper and lower lines between which they were situated.

The upper line represents situations where the nutrient concerned is the main yield-limiting factor. Thus that nutrient is maximally diluted in the plant and the yield is the highest possible given the amount of absorbed nutrient. These lines are indicated by YND, YPD and YKD in the graphs for N,P and $\mathrm{K}$, respectively, where $\mathrm{Y}$ stands for yield and $\mathrm{D}$ for diluted. They are practically identical to those found for various cereals by Van Keulen and Van Heemst (1982).

The lower lines represent situations where the nutrient concerned is excessively available, e.g. in case of overdressing. The nutrient in the plant is maximally accumulated. The yield is limited by one or more growth factors other than the nutrient concerned. The yields are indicated by YNA, YPA and YKA, where A stands for accumulated.

Sometimes points were found below the lower lines in the diagrams. They are representative for circumstances where growth has been disturbed during or after flowering. The plants grew normally and were able to take up the nutrient, but due to drought, lodging, pests, diseases and the like the process
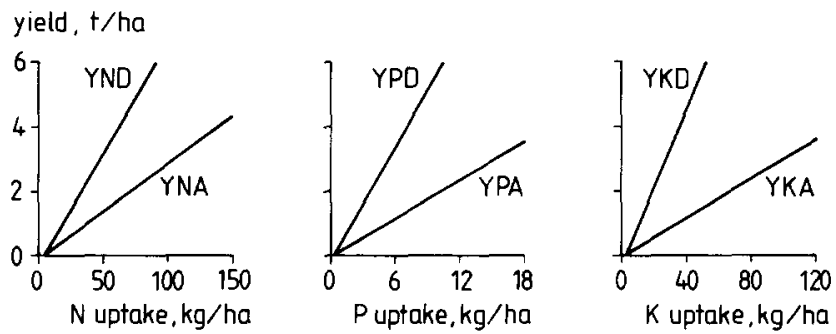

Fig. 1. Relationships between grain yield of maize and the uptake of nitrogen, phosphorus and potassium. The upper lines, YND, YPD and YKD, represent the yields with maximum dilution and the lower lines, YNA, YPA and YKA, those with maximum accumulation of nitrogen, phosphorus and potassium in the crop. For explanation see text. 
of kernel filling was hampered. This was reflected by the low fraction of kernels in total dry-matter production (low harvest index), as shown by Boxman et al. (1985). It is obvious that such points do not refer to normal uptakeyield relationships.

The lines in the diagrams of Fig. 1 do not go through the origin. When maize takes up very small quantities of nutrients, there is some growth, but the plants are not able to form cobs or grains. The minimum uptakes required to produce any grain are about $5 \mathrm{~kg} \mathrm{~N}, 0.4 \mathrm{~kg} \mathrm{P}$ and $2 \mathrm{~kg} \mathrm{~K}$ per ha. This is taken into account in the equations for calculating yields from uptake data (Table IV), discussed below in Step 3.

\section{FRAMEWORK OF THE SYSTEM}

The system comprises a number of successive steps: (1) assessment of the potential supply of nitrogen, phosphorus and potassium on the basis of chemical soil data; (2) calculation of the actual uptakes of nitrogen, phosphorus and potassium, as fractions of the potential supplies determined in Step 1; (3) designation of yield ranges as functions of the actual uptakes of nitrogen, phosphorus and potassium determined in Step 2; (4) calculation of the ultimate yield estimate by combining the three yield ranges established in Step 3.

For Steps 1 and 3 the empirical relationships discussed above are used. For Steps 2 and 4 empirical relationships could not be established because appropriate experimental data were almost completely lacking. The equations used in the calculations in these steps have been derived from theoretical considerations.

The four successive steps are described in the following sections.

STEP 1: CHEMICAL SOIL PROPERTIES AND POTENTIAL SUPPLIES.

The empirical equations are given in Table II. The potential supply of each of the nutrients nitrogen, phosphorus, and potassium proved related to $\mathrm{pH}$ but in different ways. This is expressed in the correction factors $f \mathrm{~N}, f \mathrm{P}$ and $f \mathrm{~K}$ (Table II and Fig. 2). For convenience the coefficients in eqs. 4,5 and 6 were chosen in such a way that $f \mathrm{~N}, f \mathrm{P}$ and $f \mathrm{~K}$ have values between 0 and 1 for $\mathrm{pH}\left(\mathrm{H}_{2} \mathrm{O}\right)$ ranging from 4.5 to 7 .

The potential supply of nitrogen increases with increasing $\mathrm{pH}$, corresponding with an increase in mineralization rate. If the $\mathrm{C}-\mathrm{N}$ ratio is 10 , eq. 1 is identical to eq. 7. From these equations it follows that the supply of nitrogen per growing season equals $2.72,2.04$, and $1.36 \%$ of total organic nitrogen in $2.5 \cdot 10^{6} \mathrm{~kg}$ soil $(0-20 \mathrm{~cm})$ per ha, at $\mathrm{pH}\left(\mathrm{H}_{2} \mathrm{O}\right)$ values of 7,6 , and 5 , respectively.

For the calculation of the potential supply of phosphorus about fifteen different equations have been tested. The presented eqs. 2 and 8 gave the best fit 


\section{TABLE II}

Equations for calculating the potential supply of nitrogen (SN), phosphorus (SP) and potassium (SK) by a soil (Step 1) (potential supply is expressed in $\mathrm{kg} / \mathrm{ha}$ of $\mathrm{N}, \mathrm{P}$, and $\mathrm{K}$, respectively; organic carbon and organic nitrogen in $\mathrm{g} / \mathrm{kg}$, P-Olsen and total $\mathrm{P}$ in $\mathrm{mg} / \mathrm{kg}$, and exchangeable potassium in $\mathrm{mmol} / \mathrm{kg}$; sample depth is $0-20 \mathrm{~cm}$ )

\begin{tabular}{ll}
\hline $\mathrm{SN}=f \mathrm{~N} \times 6.8 \times$ org. $\mathrm{C}^{* 1}$ & (eq. 1$)$ \\
$\mathrm{SP}=f \mathrm{P} \times 0.35 \times$ org. $\mathrm{C}+0.5 \times \mathrm{P}-\mathrm{Olsen}{ }^{* 2}$ & (eq. 2$)$ \\
$\mathrm{SK}=\frac{f \mathrm{~K} \times 400 \times \text { exch. } \mathrm{K}}{2+0.9 \times \text { org. } \mathrm{C}}$ & (eq. 3$)$ \\
$f=$ correction factor related to $\mathrm{pH}\left(\mathrm{H}_{2} \mathrm{O}\right):$ & \\
$\mathrm{N}=0.25(\mathrm{pH}-3)$ & (eq.4) \\
$f \mathrm{P}=1-0.5(\mathrm{pH}-6)^{2}$ & (eq. 5$)$ \\
$f \mathrm{~K}=0.625(3.4-0.4 \mathrm{pH})$ & (eq.6) \\
\hline
\end{tabular}

"Instead of organic carbon, organic nitrogen can be used:

$\mathrm{SN}=f \mathrm{~N} \times 68 \times$ org. $\mathrm{N}$

(eq.7)

${ }^{*}$ If total $P$ is known, it is preferred (see text) to calculate the phosphorus supply with:

$\mathrm{SP}=f \mathrm{P} \times 0.014 \times$ total $\mathrm{P}+0.5 \times \mathrm{P}-$ Olsen

(eq.8)

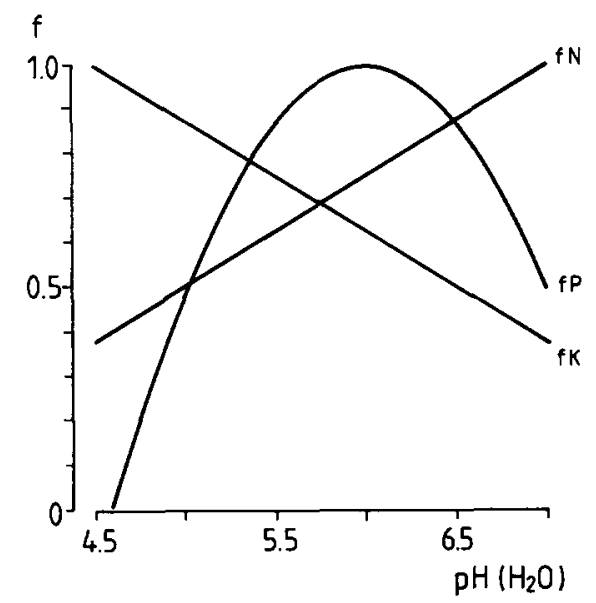

Fig. 2. The effect of $\mathrm{pH}\left(\mathrm{H}_{2} \mathrm{O}\right)$ on the potential supplies of nitrogen, phosphorus and potassium, expressed in the $\mathrm{pH}$-correction factors $f \mathrm{~N}, f \mathrm{P}$, and $f \mathrm{~K}$, respectively (see Table II).

with the experimental data. Organic carbon is used in eq. 2 as a substitute for total $P$, that is seldom determined. Comparison of eqs. 2 and 8 shows that the ratio of total $P(\mathrm{mg} / \mathrm{kg})$ and organic carbon $(\mathrm{g} / \mathrm{kg})$ is set at 25 . This value is found in many unfertilized soils. Upon prolonged application of phosphorus fertilizers, the ratio between organic carbon and total $P$ changes, and then the supply of phosphorus can be calculated only with eq. 8 . The expression for $f \mathrm{P}$ (eq. 5) is parabolic, showing an optimum at $\mathrm{pH} 6$ and zero values for $\mathrm{pH} 4.6$ 
and 7.4. Between $\mathrm{pH} 5.5$ and $6.5, f \mathrm{P}$ is more than 0.875 , indicating a rather wide range of a relatively high availability of phosphorus.

The potential supply of potassium is negatively related to $\mathrm{pH}$ and organic carbon content. The main reason probably is that increasing $\mathrm{pH}$ or increasing organic carbon content causes the effective CEC to increase as well. Hence, given a certain amount of exchangeable potassium, the relative potassium saturation decreases, so that potassium is less available to plants. Higher values of CEC are also brought about by an increase in clay content. Because carbon and clay contents are usually positively correlated, in eq. 3 only organic carbon is included. The effects of $\mathrm{pH}$, organic carbon and clay contents are discussed in a review article by Van Diest (1978), supporting the way the effects of $\mathrm{pH}$ and organic carbon on potassium supply are expressed in eqs. 3 and 6 . There are indications that eqs. 3 and 6 underestimate the supply of potassium in acid light-textured soils, low in organic carbon, and in soils high in organic carbon that contain allophane. At present, the number of data is still too small to adjust the equations.

The equations shown in Table II proved satisfactory for data from Kenya and Suriname, so they are used in this paper.

\section{STEP 2: POTENTIAL SUPPLY AND ACTUAL UPTAKE}

The relationships between the potential supply and the actual uptake of a nutrient were based on the following considerations.

The nutrients are first compared in pairs. Thus, the relation between the actual uptake and the potential supply of nitrogen is calculated twice: as depending on the potential supply of phosphorus and as depending on the potential supply of potassium. Likewise, the actual uptake of phosphorus is calculated as depending on the potential supplies of nitrogen and potassium, and that of potassium as depending on the potential supplies of nitrogen and phosphorus. This results in two estimates of the actual uptake for each of the three nutrients. The lower of the two estimates is considered the more realistic, in conformity with the law of the minimum.

The calculation procedure is illustrated by the example of the relationship between the potential supply and the actual uptake of nitrogen, as affected by the supply of phosphorus (Fig. 3 ). Along the abscissa the potential supply of nitrogen ( $\mathrm{SN}$ ), and along the ordinate the actual uptake of nitrogen (UN) is plotted. The potential supply of phosphorus is assumed to be constant; in the example of Fig. 3 it is $10.9 \mathrm{~kg}$ per ha.

Three situations are distinghuished. In situation A the potential supply of nitrogen is very small and in situation $C$ very large compared to the potential supply of phosphorus, and situation B is between these extremes. It is likely that in situation $A$ all supplied nitrogen is taken up ( $U N=S N)$, while in situation $C$ all supplied phosphorus is taken up ( $\mathrm{UP}=\mathrm{SP})$ and a further in- 


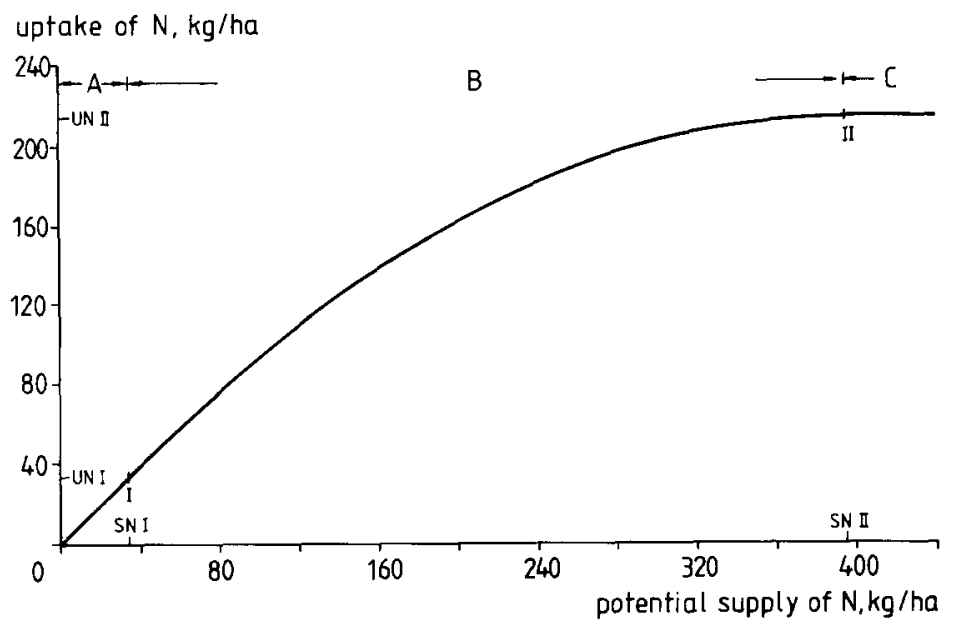

Fig. 3. Calculation of the actual uptake of nitrogen, as depending on a varying potential supply of nitrogen and a fixed potential supply of phosphorus. For explanation of situations, A,B and C, see text.

\section{TABLE III}

Equations for calculating grain yields ( $12 \%$ moisture) of maize from actual uptakes of nitrogen (UN), phosphorus (UP) and potassium (UK)

\begin{tabular}{l} 
YNA $=30 \times(\mathrm{UN}-5)$ \\
$\mathrm{YND}=70 \times(\mathrm{UN}-5)$ \\
$\mathrm{YPA}=200 \times(\mathrm{UP}-0.4)$ \\
$\mathrm{YPD}=600 \times(\mathrm{UP}-0.4)$ \\
$\mathrm{YKA}=30 \times(\mathrm{UK}-2)$ \\
$\mathrm{YKD}=120 \times(\mathrm{UK}-1)$ \\
\hline
\end{tabular}

YNA and YND (YPA and YPD, YKA and YKD) are yields obtained when nitrogen (phosphorus, potassium) in the crop is maximally accumulated and diluted, respectively. Yields and uptakes are expressed in $\mathrm{kg}$ per ha.

crease in the potential supply of nitrogen does not result in an additional nitrogen uptake. The boundary between situation A and B is Point I and that between situation $B$ and $C$ is Point II.

In situation $A$ the maximum yield that could be obtained with the supplied nitrogen, which according to eq. 10 (Table III) equals $70(\mathrm{SN}-5)$, is smaller than the yield that would be obtained if all supplied phosphorus were taken up and phosphorus were maximally accumulated in the crop. The latter yield would be 200 (SP - 0.4) according to eq. 11 (Table III); for the present example it is $2100 \mathrm{~kg}$. Hence, at Point I it holds: $70(\mathrm{SN}-5)=200(\mathrm{SP}-4)$. The potential supply of nitrogen at Point I, SN I, and the actual uptake of N, UN $I$, are thus: $\mathrm{SN} I=U N \mathrm{I}=5+(\mathrm{SP}-0.4)(200 / 70)$. For the example it is $35 \mathrm{~kg}$ 
$\mathrm{N}$. This implies that as long as the potential supply of nitrogen is less than about three times that of phosphorus, all supplied nitrogen is taken up.

In situation $C$ nitrogen will be maximally accumulated in the crop and phosphorus maximally diluted; the corresponding yield would be 600 (SP -4), (eq. 12); this is $6300 \mathrm{~kg}$ in the example. Beyond Point II, the actual uptake of nitrogen does not increase. Thus at Point II, $600(\mathrm{SP}-0.4)$ equals $30(\mathrm{UN}-5)$, or UN II $=5+(\mathrm{SP}-0.4)(600 / 30)$, being $215 \mathrm{~kg} \mathrm{~N}$ in the example. This implies that the maximum uptake of nitrogen is about twenty times the potential supply of phosphorus.

Between Point I and Point II, dUN/dSN, or more precisely, d(UN-UN I) $/ \mathrm{d}(\mathrm{SN}-\mathrm{SN}$ I) decreases from one to zero. For lack of better alternatives we assume that this decrease is linear:

$\mathrm{d}(\mathrm{UN}-\mathrm{UN} \mathrm{I}) / \mathrm{d}(\mathrm{SN}-\mathrm{SN} \mathrm{I})=1-q(\mathrm{SN}-\mathrm{SN} \mathrm{I})$

where $\mathrm{SN} \mathrm{I}=5+(\mathrm{SP}-0.4)(200 / 70)$

Integration yields a parabola:

$(\mathrm{UN}-\mathrm{UN} \mathrm{I})=(\mathrm{SN}-\mathrm{SN} \mathrm{I})-0.5 q(\mathrm{SN}-\mathrm{SN} \mathrm{I})^{2}+\mathrm{C}$

The integration constant, found by substitution of $(\mathrm{SN}-\mathrm{SN} \mathrm{I})=0$, is zero, and hence:

$\mathrm{UN}=\mathrm{UN} \mathrm{I}+(\mathrm{SN}-\mathrm{SN} \mathrm{I})-0.5 q(\mathrm{SN}-\mathrm{SN} \mathrm{I})^{2}$

or, because UN I equals SN I:

$\mathrm{UN}=\mathrm{SN}-0.5 q(\mathrm{SN}-\mathrm{SN} \mathrm{I})^{2}$

The unknown $q$ can be expressed in SN I and SN II. At Point II, it holds:

$1-q(\mathrm{SN} I I-\mathrm{SN} \mathrm{I})=0$.

Thus:

$q=1 /(\mathrm{SN} \mathrm{II}-\mathrm{SN} \mathrm{I})$ and $\mathrm{UN} \mathrm{II}=0.5(\mathrm{SN} \mathrm{I}+\mathrm{SN} \mathrm{II})$.

Now SN II can be expressed in SP by combining the equation for SN I with the two equations for UN II.

It follows:

$\mathrm{SN} I I=5+(\mathrm{SP}-0.4)(2 \times 600 / 30-200 / 70)$

In the example SN II is $395 \mathrm{~kg}$. This implies that the uptake of nitrogen remains at a value of about twenty times the potential supply of phosphorus, when the potential supply of nitrogen is more than 37 times the potential supply of phosphorus.

Substitution of $q$ and SN II yields for UN between Points I and II: 


\section{TABLE IV}

Equations for the calculation of the actual uptake of Nutrient 1 as a function of the potential supplies of Nutrients 1 and 2 (Step 2)

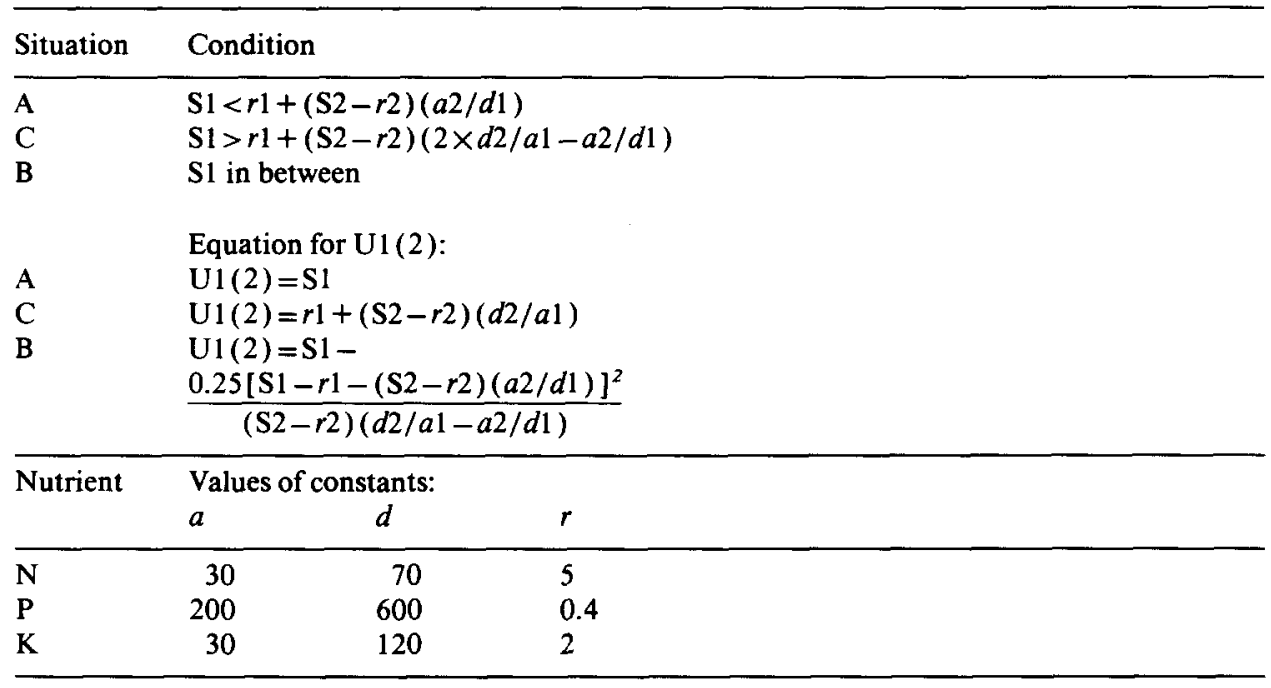

S 1 and $S 2$ are the potential supplies of Nutrients 1 and 2. U1(2) stands for the actual uptake of Nutrient 1 , as depending on the potential supply of Nutrient 2 . The symbols $a, d$ and $r$ refer to the constants in the equations of Table III; their values are also indicated. Situations A, B and C are indicated in Fig. 3. For explanation see text.

$\mathrm{UN}=\mathrm{SN}-\frac{0.25(\mathrm{SN}-5-(\mathrm{SP}-0.4)(200 / 70))^{2}}{(\mathrm{SP}-0.4)(600 / 30-200 / 70)}$

The relationships for the other nutrients are derived in a similar way. Table IV gives general equations and boundary conditions.

\section{STEP 3. ACTUAL UPTAKE OF NUTRIENTS AND YIELD RANGES}

Yield ranges corresponding with the actual uptake of nitrogen, phosphorus and potassium are calculated with the equations of Table III. These equations refer to the lines in Fig. 1, as explained in the section on experimental data.

The ranges in yields that can be calculated from the calculated actual uptakes of nitrogen, phosphorus and potassium often differ considerably, but they usually have an overlap. By systematic comparison of the possible yields, the ranges are narrowed to one yield estimate. 
The procedure for combining the yield ranges calculated in Step 3 consists of two parts. First the yield ranges are combined in pairs (nitrogen and phosphorus, nitrogen and potassium, phosphorus and potassium) and second, the yields found for the paired nutrients are averaged. This average is the ultimate yield estimate.

The yields estimated from pairs of yield ranges should be within the overlap of the ranges and should not exceed the upper limit of the yield range of the third nutrient.

\section{Combining yield ranges for two nutrients.}

In Fig. 4, the combining of pairs of yield ranges is explained for the example of nitrogen and phosphorus. The uptake of nitrogen is plotted along the abscissa. The corresponding yield ranges lie between the lines YND and YNA, where $Y N D=70(U N-5)$ and $Y N A=30(U N-5)$. (eqs. 10 and 9 in Table III). The uptake of $P$ is set at $10.9 \mathrm{~kg}$; the upper and the lower limit of the corresponding yield range are $Y P D=600(10.9-0.4)=6300 \mathrm{~kg}$, and $\mathrm{YPA}=200$ $(10.4-0.4)=2100 \mathrm{~kg}$, respectively (eqs. 12 and 11 in Table III). The graph shows that YND would be lower than YPA when the uptake of nitrogen would be less than $5+\mathrm{YPA} / 70=35 \mathrm{~kg}$ (UN III). Thus, $35 \mathrm{~kg}$ is the minimum uptake of nitrogen that is possible for a crop that takes up $10.9 \mathrm{~kg} \mathrm{P}$. In such conditions nitrogen will be maximally diluted in the crop, and the yield for the combination of nitrogen and phosphorus uptakes, indicated by YNP, can be estimated as YND (Point III).

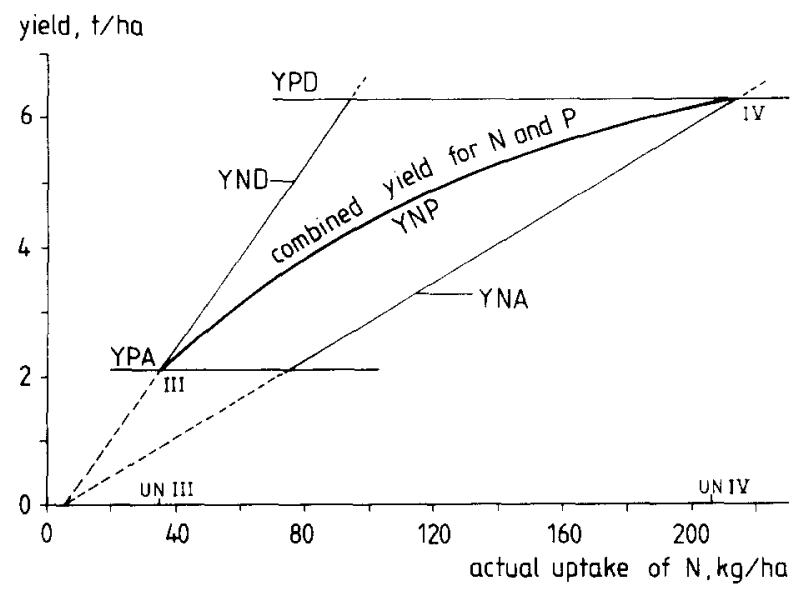

Fig. 4. Calculation of the yield for a pair of nutrients (nitrogen and phosphorus). For explanation see text. 
The maximum uptake of nitrogen is $5+\mathrm{YPD} / 30=215 \mathrm{~kg} \mathrm{~N}$ (UN IV). At a higher nitrogen uptake, YNA would be higher than $6300 \mathrm{~kg}$ and that is impossible. At Point IV the estimate for YNP equals YPD $(6300 \mathrm{~kg})$. So, for a crop that takes up $10.9 \mathrm{~kg} \mathrm{P}$, the uptake of nitrogen must lie between 35 (UN III) and $215 \mathrm{~kg}$ (UN IV). Between Points III and IV the yield ranges for nitrogen and phosphorus partially overlap and YNP must lie in the overlap, i.e. below the lines YND and YPD and above the lines YNA and YPA. The simplest way to estimate YNP in such cases would be to assume that it lies on the straight line connecting points III and IV. Yield-uptake relationships, as found in fertilizer trials, however, generally have a more curvilinear shape. Many equations have been used in course of time to describe such curvilinear relationships. We assumed that YNP follows a parabolic curve between points III and IV. A parabola was chosen because is has a distinct, non-asymptotic maximum, and is a relatively simple equation. The parabola can be represented by $(\mathrm{YNP}-\mathrm{YPA})=b(\mathrm{UN}-\mathrm{UN}$ III $)-c(\mathrm{UN}-\mathrm{UN} \text { III })^{2}$.

The unknowns $b$ and $c$ of this equation can be expressed in (YPD-YPA), which is the maximum value of (YNP - YPA), and (UN IV-UN III) which is the corresponding value of (UN-UN III). This results in:

$b=2(\mathrm{YPD}-\mathrm{YPA}) /(\mathrm{UN}$ IV $-\mathrm{UN}$ III $)$, and

$c=(\mathrm{YPD}-\mathrm{YPA}) /(\mathrm{UN} \text { IV }-\mathrm{UN} \mathrm{III})^{2}$

After substitution of 5+YPA/70 for UN III and 5+YPD/30 for UN IV, the parabola can be written as:

$$
\begin{aligned}
\mathrm{YNP}= & \mathrm{YPA}+\frac{2(\mathrm{YPD}-\mathrm{YPA})(\mathrm{UN}-5-\mathrm{YPA} / 70)}{\mathrm{YPD} / 30-\mathrm{YPA} / 70} \\
& -\frac{(\mathrm{YPD}-\mathrm{YPA})(\mathrm{UN}-5-\mathrm{YPA} / 70)^{2}}{(\mathrm{YPD} / 30-\mathrm{YPA} / 70)^{2}}
\end{aligned}
$$

The yields for the other pairs of nutrients are calculated in a similar way. The general equation and the values for the coefficients are given in Table V.

\section{Combining yield ranges for three nutrients}

The ultimate yield estimate (YE) is obtained by averaging six yields for paired nutrients. An important condition should be fulfilled, however, in that the yield calculated for any combination of two nutrients may not exceed the upper limit of the yield range of the third nutrient or any other yield limit that might result from other growth factors.

The procedure is illustrated in Fig. 5 for a maize crop that takes up $85 \mathrm{~kg}$ $\mathrm{N}, 10.9 \mathrm{~kg} \mathrm{P}$ and $62 \mathrm{~kg} \mathrm{~K}$ per ha. The corresponding yield ranges are $2400-$ $5600,2100-6300$ and $1800-7200 \mathrm{~kg} / \mathrm{ha}$. Thus the yield range for nitrogen 


\section{TABLE V}

Equation for the calculation of the maize yield (Y12) for a combination of two nutrients, taking into account the yield range of the third nutrient (Step 4)

$\mathrm{Y} 12=\mathrm{Y} 2 \mathrm{~A}+\frac{2 \times(\mathrm{Y} 2 \mathrm{D}-\mathrm{Y} 2 \mathrm{~A})(\mathrm{U} 1-r 1-\mathrm{Y} 2 \mathrm{~A} / d 1)}{\mathrm{Y} 2 \mathrm{D} / a 1-\mathrm{Y} 2 \mathrm{~A} / d 1}-\frac{(\mathrm{Y} 2 \mathrm{D}-\mathrm{Y} 2 \mathrm{~A})(\mathrm{U} 1-r 1-\mathrm{Y} 2 \mathrm{~A} / d 1)^{2}}{(\mathrm{Y} 2 \mathrm{D} / a 1-\mathrm{Y} 2 \mathrm{~A} / d 1)^{2}}$

where:

$\mathrm{Y} 2 \mathrm{~A}=$ yield corresponding with maximum accumulation of Nutrient 2

$\mathrm{Y} 2 \mathrm{D}=$ yield corresponding with maximum dilution of Nutrient 2

$\mathrm{U} 1=$ actual uptake of Nutrient 1

Note. If $Y 3 D$ is less than $Y 2 D, Y 3 D$ should be substituted for $Y 2 D$, where $Y 3 D=$ yield corresponding with maximum dilution of Nutrient 3.

All values are in $\mathrm{kg}$ per ha. For the values of the constants $a, d$ and $r$, see Table IV. For explanation see text.

lies within the yield range for phosphorus, which in turn lies within the yield range of potassium. The parabola for YNP (Fig. 5, top left) is the same as that in Fig. 4. Following the procedure outlined above, the parabola for YNK (top right) would run from 1800 to $7200 \mathrm{~kg}$, exceeding the upper limit of the yield range for phosphorus (YPD). This is considered to be not realistic. Therefore, YPD instead of YKD is taken as the maximum value for the parabola for YNK. Similarly, YND is substituted for YKD in the parabola for YPK (mid right) and YND for YPD in the parabola for YKP (bottom right). The yields calculated for paired nutrients are indicated in Fig. 5 by crosses. The values for YNP, YNK, YPN, YPK, YKN and YKP are 4109, 4061, 3899, 3738,3752 and 3638 , respectively. Their average, being $3866 \mathrm{~kg} / \mathrm{ha}$ is the ultimate yield estimate for this maize crop that has taken up $85 \mathrm{~kg} \mathrm{~N}, 10.9 \mathrm{~kg}$ $P$ and $62 \mathrm{~kg} \mathrm{~K}$.

In Fig. 5 each pair of nutrients is combined twice, e.g. $N$ and $P$ in YNP and YPN. The values of YNP (4109) and YPN (3899) are not equal because the relevant parabolas have different boundaries and coefficients. For similar reasons YNK (4061) is not equal to YKN (3752), and YPK (3899) is not equal to YKP (3638).

\section{SOME EXAMPLES}

The purpose of the system outlined above is to evaluate native soil fertility using estimated maize yields as a yardstick. The results of the four successive steps (potential supply of nutrients, actual uptake of nutrients, yield ranges and yields for paired nutrients), made to arrive at these yield estimates, are shown in Table VI for a soil denoted as Soil A. In Table VII the potential supplies, actual uptakes and ultimate yield estimates of five soils are compared. Soils B to E differ in one property from Soil A, to demonstrate how these properties affect the results.

The calculated potential supplies of nutrients for Soil A (Step 1 in Table 

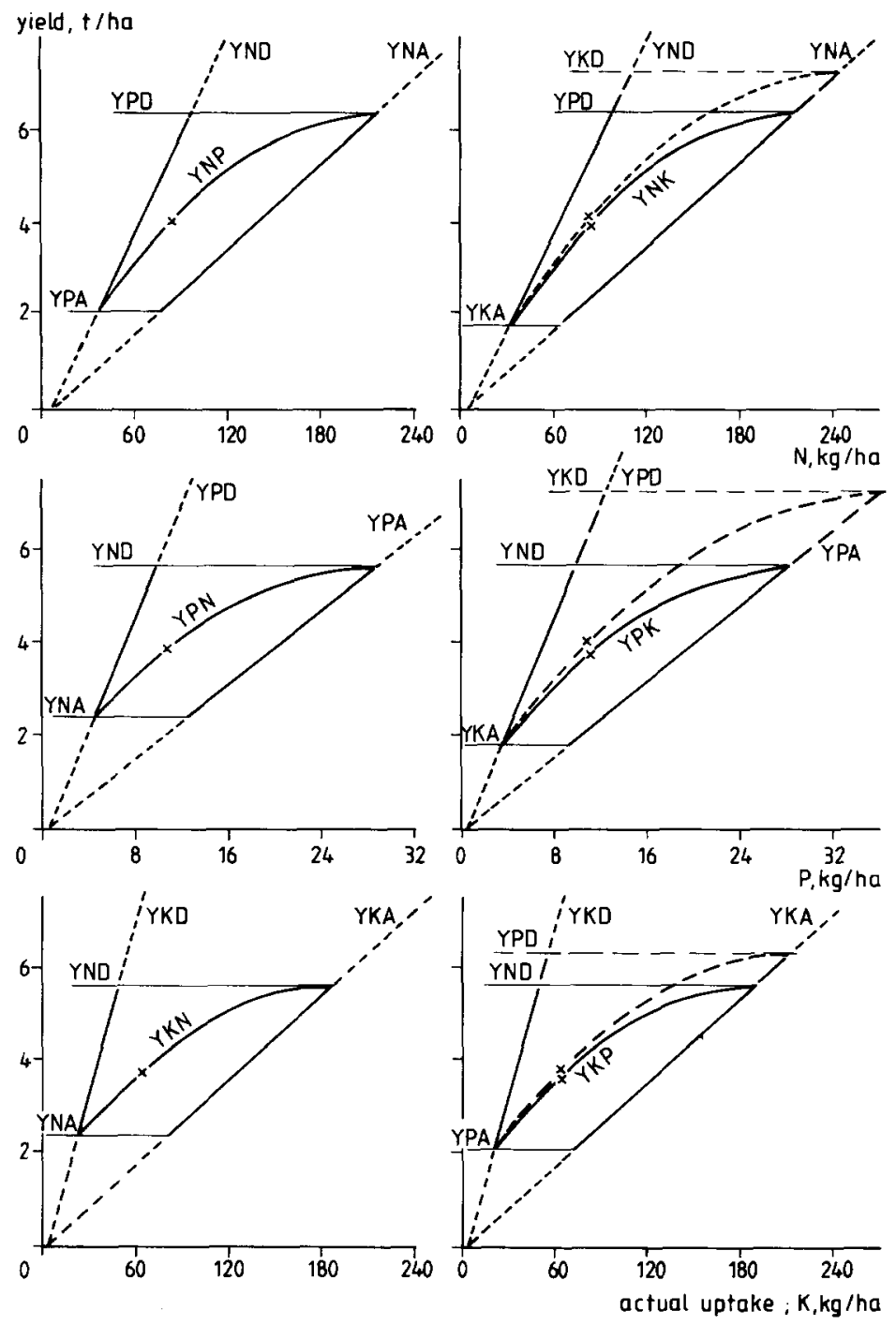

Fig. 5. Combining of yield ranges for nitrogen, phosphorus and potassium. Actual uptakes are $85 \mathrm{~kg} \mathrm{~N}, 10.9 \mathrm{~kg} \mathrm{P}$ and $62 \mathrm{~kg} \mathrm{~K}$. For the meaning of symbols see Figs. 1 and 4 . For explanation see text.

VI) are rather well balanced. Phosphorus is relatively least and potassium relatively most available. That is why in Step $2 \mathrm{UN}(\mathrm{K})$ and $U P(K)$ are higher than $U N(P)$ and $U P(N)$, respectively, why UK(P) is lower than $U K(N)$ and why in Step 3 the yield ranges for the individual nutrients rank in the order: potassium, nitrogen, phosphorus. The yield ranges have a common overlap between $3167 \mathrm{~kg} / \mathrm{ha}$ (YKA) and $5367 \mathrm{~kg} / \mathrm{ha}$ (YPD). All yields cal- 
culated for paired nutrients (Step 4) lie within this interval, and so does the ultimate yield estimate, YE.

The value of exchangeable potassium in Soil B in Table VII is half as high as in Soil A, and the same ratio is found for the calculated potential supplies of potassium (SK). The actual uptakes, UK(N) and UK(P), are close to the potential supply. The ultimate yield estimate is $530 \mathrm{~kg}$ lower than that for Soil $\mathrm{A}$, which is a modest reduction in view of the substantial lower value for exchangeable potassium.

In Soil C, P-Olsen is $4 \mathrm{mg} / \mathrm{kg}$ lower than in Soil A and hence the potential phosphorus supply is lowered by $2 \mathrm{~kg} / \mathrm{ha}$ (Table II, eq. 2). This makes phosphorus more limiting than in Soil A. As a result the actual uptake equals the potential supply of phosphorus or is very close to it; both UP(N) and UP(K) are lower than on Soil A. The ultimate yield estimate is about $600 \mathrm{~kg}$ lower than on Soil A, again a rather small reduction in yield.

In Soil D, organic carbon and hence the potential supply of nitrogen are half as high as for Soil A. The potential phosphorus supply is also lower than in Soil A, and even lower than in Soil C where P-Olsen was reduced to $1 \mathrm{mg}$ / $\mathrm{kg}$. The potential potassium supply in Soil D is larger than in Soil A (see eq. 3 in Table II). Because potassium is abundantly available, $U N(K)$ and $\mathrm{UP}(\mathrm{K})$ are larger than $\mathrm{UN}(\mathrm{P})$ and $\mathrm{UP}(\mathrm{N})$, and equal the potential supplies of nitrogen and phosphorus, respectively. The final yield estimate is about $1500 \mathrm{~kg}$ lower than on Soil A. Thus the decrease in organic carbon from 20 to $10 \mathrm{~g} / \mathrm{kg}$ has a much stronger effect on the calculated ultimate yield than the decrease in P-Olsen from 5 to $1 \mathrm{mg} / \mathrm{kg}$ or that in exchangeable potassium from 10 to $5 \mathrm{mmol} / \mathrm{kg}$.

In Soil $\mathrm{E}$, the effect of the lowering of $\mathrm{pH}$ is similar to that of the decrease in organic carbon: a reduction in the potential supplies of nitrogen and phosphorus, and an increase in potassium supply. As on Soil D, the actual uptakes of nitrogen and phosphorus are almost as large as the potential supplies. The uptakes of phosphorus and potassium are about the same as for Soil D but the uptake of nitrogen is $13 \mathrm{~kg}$ higher and the ultimate yield estimate is 272 $\mathrm{kg}$ higher. Comparison with Soil A shows that the change in $\mathrm{pH}$ from 6 to 5 causes a yield reduction of about $30 \%$.

\section{SENSITIVITY}

The above examples show that the effects of organic carbon and $\mathrm{pH}\left(\mathrm{H}_{2} \mathrm{O}\right)$ on yield outweigh the effects brought about by changes in P-Olsen or in exchangeable potassium. The same conclusion can be drawn from Fig. 6 . In this figure, calculated yields strongly increase by an increase in organic carbon. An exception forms the interval between 20 and $30 \mathrm{~g} / \mathrm{kg}$ of organic carbon for the curve representing soils with $\mathrm{pH}\left(\mathrm{H}_{2} \mathrm{O}\right) 6$, P-Olsen $10 \mathrm{mg} / \mathrm{kg}$ and exchangeable potassium $5 \mathrm{mmol} / \mathrm{kg}$. Here potassium is so limiting that the in- 


\section{TABLE VI}

Potential supply (Step 1 ) and actual uptake (Step 2) of nitrogen, phosphorus and potassium, yield ranges (Step 3), yields calculated for paired nutrients (Step 4) and ultimate yield estimate (YE) for unfertilized maize on Soil A, with pH $\left(\mathrm{H}_{2} \mathrm{O}\right) 6$, org. $\mathrm{C} 20 \mathrm{~g} / \mathrm{kg}, \mathrm{P}-\mathrm{Olsen} 5 \mathrm{mg} / \mathrm{kg}$ and exchangeable $\mathrm{K}$ $10 \mathrm{mmol} / \mathrm{kg}$ (data on supply, uptake and yields are in $\mathrm{kg} / \mathrm{ha}$ )

\begin{tabular}{|c|c|c|c|c|c|c|}
\hline Step 1 & SN & 102 & SP & 9.5 & SK & 125 \\
\hline \multirow[t]{2}{*}{ Step 2} & $\mathrm{UN}(\mathrm{P})$ & $94^{* 1}$ & $\mathrm{UP}(\mathrm{N})$ & 9.3 & UK(N) & 113 \\
\hline & UN(K) & $1 \overline{01}$ & $\mathrm{UP}(\mathrm{K})$ & $\overline{9.5}$ & UK(P) & $\underline{108}$ \\
\hline \multirow[t]{2}{*}{ Step 3} & YNA & 2668 & YPA & 1789 & YKA & 3167 \\
\hline & YND & 6225 & YPD & 5367 & YKD & 12669 \\
\hline \multirow[t]{3}{*}{ Step 4} & YNP & 4135 & YPN & 3766 & YKN & 4776 \\
\hline & YNK & 4370 & YPK & 3973 & YKP & 4652 \\
\hline & YE & 4279 & & & & \\
\hline
\end{tabular}

"The underlined data are used in further calculations.

\section{TABLE VII}

Potential supply and actual uptake of nitrogen, phosphorus and potassium, and ultimate yield estimate (YE) for unfertilized maize on soils with the specified chemical properties

\begin{tabular}{lcccrr}
\hline Soils: & A & B & C & D & E \\
\hline pH $\left(\mathrm{H}_{2} \mathrm{O}\right)$ & 6 & 6 & 6 & 6 & 5 \\
Org. C $(\mathrm{g} / \mathrm{kg})$ & 20 & 20 & 20 & 10 & 20 \\
P-Olsen $(\mathrm{mg} / \mathrm{kg})$ & 5 & 5 & 1 & 5 & 5 \\
exch. K (mmol/kg) & 10 & 5 & 10 & 10 & 10 \\
Potential supply of nutrients: & 102 & 102 & 102 & 51 & \\
SN & 9.5 & 9.5 & 7.5 & 6.0 & 68 \\
SP & 125 & 63 & 125 & 227 & 175 \\
SK & & & & & 6.0
\end{tabular}

Actual uptake of nutrients; the underlined values are used in further calculations

\begin{tabular}{|c|c|c|c|c|c|}
\hline $\mathrm{UN}(\mathrm{P})$ & 94 & 94 & $\underline{90}$ & $\underline{49}$ & $\underline{62}$ \\
\hline UN (K) & 101 & 96 & $1 \overline{01}$ & 51 & 68 \\
\hline $\mathrm{UP}(\mathrm{N})$ & 9.3 & 9.3 & 7.4 & 5.8 & 5.9 \\
\hline$U P(K)$ & 9.5 & 9.2 & 7.5 & 6.0 & 6.0 \\
\hline UK(N) & 113 & 61 & 113 & 109 & 128 \\
\hline$U K(P)$ & $\underline{108}$ & $\underline{59}$ & 101 & $\overline{114}$ & $\underline{110}$ \\
\hline \multicolumn{6}{|c|}{ Ultimate yield estimate: } \\
\hline YE & 4279 & 3748 & 3688 & 2747 & 3019 \\
\hline
\end{tabular}

Soil $A$ is the reference soil from Table VI, the other soils differ in one property from Soil A. Data on supply, uptake and yield are in $\mathrm{kg} / \mathrm{ha}$. 


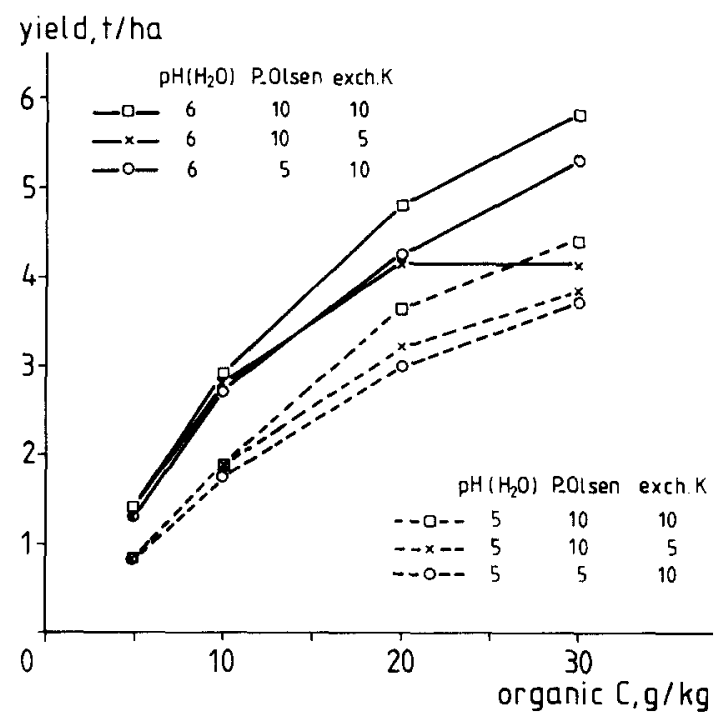

Fig. 6. Relationships between calculated yields and organic carbon for soils with the indicated values of $\mathrm{pH}\left(\mathrm{H}_{2} \mathrm{O}\right), \mathrm{P}-\mathrm{Olsen}$ and exchangeable potassium.

crease in the potential supplies of nitrogen and phosphorus, brought about by the rise in organic carbon from 20 to $30 \mathrm{~g} / \mathrm{kg}$, does not result in a higher yield.

Similar expressions of the law of the minimum are found in Fig. 6 at low levels of organic carbon; the effects of P-Olsen or exchangeable potassium on yield are then absent or negligable.

Fig. 6 clearly demonstrates that there is little sense in trying to interpret values of a certain soil property, if not at the same time the values of the other soil properties are considered. For the same reason it is impossible to give unequivocal indications of the sensitivity of calculated yield to variations in the values of of the diagnostic soil properties. The effects on maize yields caused by a change in organic carbon of $1 \mathrm{~g} / \mathrm{kg}$, or in P-Olsen of $1 \mathrm{mg} / \mathrm{kg}$, or in exchangeable potassium of $0.1 \mathrm{mmol} / \mathrm{kg}$, range from zero to about $500 \mathrm{~kg}$ per ha, depending on the values of the other soil properties.

\section{CONCLUDING REMARKS}

The empirical relationships used in Steps 1 and 3 were derived from field trials. Most of these trials provided data for only parts of the equations. To test the system, complete sets of data on the appropriate soil properties and on yields of unfertilized maize are required. We had only a restricted number of trials with suitable complete data sets at our disposal. These trials, however, had also been used, together with many others, to develop the equations and therefore their results do not form a completely independent test. The 
QUEFTS system is now being tested in projects of the Agricultural University of Wageningen that are carried out in Cote d'Ivoire and Costa Rica, and in some projects in other countries. The objective is to find out whether and in what way the coefficients used in the equations have to be adjusted for different climatic and soil conditions and for different crops. The results obtained so far indicate that the QUEFTS system is a promising tool in evaluating native fertility of tropical soils. The methodology - successive calculations of potential nutrient supply, actual nutrient uptake, yield ranges and combining yield ranges in pairs and eventually into one yield estimate - may be applied to other crops than maize, to soils with property values outside the range for which the here presented equations were developed, and to other climate regions. The present system is meant for tropical soils because the relationships between chemical soil properties and potential supply of nutrients (Step 1) were established for tropical soils. The equations used in Steps 2, 3 and 4 are likely to be valid for maize wherever it is grown. In principle, it is also possible to include other nutrients than nitrogen, phosphorus and potassium, provided appropriate equations can be found for such nutrients.

For the soils of Kilifi District, Kenya, Smaling and Janssen (1987) compared QUEFTS with the qualitative Fertility Capability Classification (FCC) system, described by Sanchez et al. (1982). The systems proved supplemental: QUEFTS gives quantitative information on yields, whereas FCC qualitatively indicates the factors that might cause a discrepancy between calculated and measured yields.

The Centre for World Food studies (1985) has shown that the QUEFTS system can easily be used in computerized modelling of crop production. The yields calculated with QUEFTS refer to soils with no severe limitations others than short supplies of nitrogen, phosphorus and potassium. Limitations due to temperature, solar radiation and water supply are dealt with in simulation models, such as the one presented by Van Keulen and Wolf (1986). The yield limits found in such models can be introduced in QUEFTS via the equations of Steps 1 and 3.

\section{REFERENCES}

Boxem, H.W., de Meester, T. and Smaling, E.M.A. (Editors), 1987. Soils of the Kilifi Area, Kenya. Agric. Res. Rept. 929, Pudoc, Wageningen, 249 pp. +8 appendices.

Boxman, O., Goense, D., Janssen, B.H., Neeteson, J.J. and Wienk, J.F., 1985. The effect of moisture stress on the response to nitrogen by maize in the humid tropics of Suriname. In: B.T. Kang and J. van der Heide (Editors), Nitrogen Management in Farming Systems in Humid and Subhumid Tropics. Institute for Soil Fertility (IB), Haren and IITA, Ibadan. IB, Haren, pp. 199-214.

Centre for World Food Studies, 1985. Potential Food Production Increases from Fertilizer Aid: A Case Study of Burkina Faso, Ghana, and Kenya. A study prepared for FAO, Wageningen, Vol. I, 48 pp., Vol. II, 35 maps. 
FAO, 1976. A Framework for Land Evaluation. FAO Soils Bull. 32, FAO, Rome, 72 pp.

Guiking, F.C.T., Janssen, B.H. and Van der Eijk, D., 1983. Soil fertility. Nutrient availability. In: W.G. Wielemaker and H.W. Boxem (Editors), Soils of the Kissii Area, Kenya. Agric. Res. Rept. 922, Pudoc, Wageningen, pp. 36-38, 76-89, 110-111, 194-196.

Janssen, B.H., Guiking, F.C.T., Van der Eijk, D., Smaling, E.M.A. and Van Reuler, H., 1986. A new approach to evaluate the chemical fertility of tropical soils. Trans. XIII Congr. ISSS, Hamburg, Vol. III, pp. 791-792.

Sanchez, P.A., Couto, W. and Buol, S.W., 1982. The fertility capability soil classification system: interpretation, applicability and modification. Geoderma, 27: 283-309.

Smaling, E.M.A. and Janssen, B.H., 1987. Soil fertility. Nutrient availability. In: H.W. Boxem, T. de Meester and E.M.A. Smaling (Editors), Soils of the Kilifi Area, Kenya. Agric. Res. Rept. 929, Pudoc, Wageningen, pp. 109-117, 131-132.

Van Diest, A., 1978. Factors affecting the availability of potassium in soils. Proc. 11 th Congr. Int. Potash Inst. Bern, pp. 75-97.

Van Keulen, H. and Van Heemst, H.D.J., 1982. Crop Response to the Supply of Macronutrients. Agric. Res. Rept. 916, Pudoc, Wageningen, 46 pp.

Van Keulen, H. and Wolf J. (Editors), 1986. Modelling of agricultural production: weather, soils and crops. Simulation Monographs, Pudoc, Wageningen, $478 \mathrm{pp}$.

Wielemaker, W.G. and Boxem, H.W. (Editors), 1983. Soils of the Kisii Area, Kenya. Agric. Res. Rept. 922, Pudoc, Wageningen, 208 pp. + 5 maps + separate appendix. 